\title{
The Development of a Mathematical Model for the Prediction of Corrosion Rate Behaviour for Mild Steel in 0.5 M Sulphuric Acid
}

\author{
I. Y. Suleiman, ${ }^{1}$ O. B. Oloche, ${ }^{2}$ and S. A. Yaro $^{3}$ \\ ${ }^{1}$ Department of Metallurgical Engineering, Waziri Umaru Federal Polytechnic, Birnin Kebbi, Nigeria \\ ${ }^{2}$ Department of Mechanical Engineering, University of Abuja, Abuja, Nigeria \\ ${ }^{3}$ Department of Metallurgical and Materials Engineering, Ahmadu Bello University, Zaria, Nigeria
}

Correspondence should be addressed to I. Y. Suleiman; onoruoizadanjumas@yahoo.co.uk

Received 5 November 2012; Accepted 26 November 2012

Academic Editors: Q. Qu and E. Stupnisek-Lisac

Copyright (C) 2013 I. Y. Suleiman et al. This is an open access article distributed under the Creative Commons Attribution License, which permits unrestricted use, distribution, and reproduction in any medium, provided the original work is properly cited.

\begin{abstract}
The effect of varying temperature, concentration, and time on the corrosion rate of mild steel in $0.5 \mathrm{M} \mathrm{H}_{2} \mathrm{SO}_{4}$ acid with and without (wild jute tree) grewia venusta plant extract has been investigated by weight loss. The temperature, concentration of inhibitor and time were varied in the range of $0-10 \% \mathrm{v} / \mathrm{v}$ at $2 \% \mathrm{v} / \mathrm{v}$ interval, $30-70^{\circ} \mathrm{C}$ at $20^{\circ} \mathrm{C}$ interval, and $45-270$ minutes at 45 minutes interval respectively. Scanning electron microscope was used to analyze the morphology of the sample surface. Linear regression equation and analysis of variance (ANOVA) were employed to investigate the influence of process parameters on the corrosion rate of the samples. The predicted corrosion rate of the samples was found to lie close to those experimentally observed ones. The confirmation of the experiment conducted using ANOVA to verify the optimal testing parameters shows that the increase in inhibitor concentration above $2 \% \mathrm{v} / \mathrm{v}$ and time would reduce the corrosion rate. The results also showed that the increase in temperature would also increase the corrosion rate greatly and that the plant extract was very effective for the corrosion inhibition of mild steel in acidic medium.
\end{abstract}

\section{Introduction}

Steels are the most extensively used structural materials in industry. Mild steel is the most versatile general purpose material due to its good mechanical strength, easy fabricability, formability and weldability, abundance and low cost [1].

In corrosive environments, mild steel structures can be saved by coating and/or cathodic protection. The use of inhibitors is one of the most practical methods for protection against corrosion and prevention of unexpected metal dissolution and acid consumption, especially in acid solutions. Different organic and inorganic compounds have been studied as inhibitors to protect metals from corrosive attack [2].

Such compounds can adsorb onto the metal surface and block the active surface sites, thus reducing the corrosion rate. Although many synthetic compound show good anticorrosive activity, most of them are highly toxic to both human beings and the environment [3], and they are often expensive and non-biodegradable. Thus, the use of natural products as corrosion inhibitors has become a key area of research because plant extracts are viewed as an incredibly rich source of naturally synthesized chemical compounds that are biodegradable in nature and can be extracted by simple procedures with low cost.

Corrosion of mild steel and its alloys in different acid media have been extensively studied [4-6]. Recently considerable interest has been generated in the use of nitrogen, oxygen and sulphur containing organic compounds as corrosion inhibitor for mild steel in different acids [7-9].

In this work, green wild jute tree (Grewa venusta) extract was used as inhibitor. Wild jute tree from the bark of Grewa venusta, is a shrub or small tree to $10.5 \mathrm{~m}$ tall called wild jute in English, Dargaza in Hausa and belong to Tiliaceae family. It is used as fibre and the phytochemical analysis showed that both the Leaves and bark contain many compounds, such as polysaccharides, volatile oils, vitamins, tannins, minerals, alkaloids (e.g., caffeine) and polyphenols (catechins and flavonoids). It is found in the northern part of the country [10]. 
Thermodynamics and kinetics are useful parameters for analyzing systems undergoing chemical reactivity. Corroding systems are not in equilibrium and therefore thermodynamic calculation cannot be applied. Hence, from the engineering point of view, the major interest is the kinetics or rate of corrosion [11].

In this work, wild jute tree (Grewa venusta) extract was used as inhibitor. Wild jute tree from the bark of Grewa venusta is a shrub or small tree to $10.5 \mathrm{~m}$ tall called wild jute and belongs to Tiliaceae family. It is used as fibre and the phytochemical analysis showed that both the leaves and bark contain many compounds, such as polysaccharides, volatile oils, vitamins, tannins, minerals, alkaloids (e.g., caffeine), and polyphenols (catechins and flavonoids). It is found in the northern part of the country [10].

\section{Experimental Procedure}

2.1. Preparation of Mild Steel Specimen. Mild steel rods were mechanically cut into cylindrical shape of $20 \mathrm{~mm}$ by $10 \mathrm{~mm}$ with the following chemical compositions: $0.16 \% \mathrm{C}, 0.38 \%$ $\mathrm{Mn}, 0.18 \% \mathrm{Si}, 0.035 \% \mathrm{~S}, 0.034 \% \mathrm{P}$ and the remainder Fe. The specimen were polished mechanically with emery papers of 80 to 800 grades and subsequently degreased and stored in the desiccators to avoid re-oxidation. Weight of the samples was taken before and after the test.

2.2. Preparation of the Plant Extract. The leaves of the plant Grewa venusta was taken and cut into small pieces and they were dried in an air for three days and ground well into powder. The refluxed solution using ethanol was then filtered and the concentration of the stock solution is expressed in terms of (\% v/v). From the stock solution, 2$10 \% \mathrm{v} / \mathrm{v}$ concentration of the extract was prepared using $0.5 \mathrm{M}$ sulphuric acid. Similar kind of preparation has been reported in studies using aqueous plant extracts in the recent years $[12,13]$.

2.3. Weight Loss Method. The pretreated specimens' initial weights were noted and were immersed in the experimental solution (in triplicate) with the help of glass hooks at $30^{\circ} \mathrm{C}$ for a period of 270 minutes. The experimental solution used was $0.5 \mathrm{M} \mathrm{H}_{2} \mathrm{SO}_{4}$ in the absence and presence of various concentrations of the plant extract. After 270 minutes, the specimens were taken out, washed thoroughly with distilled water, dried completely and their final weights were noted. From the initial and final weights of the specimen, the loss in weight was calculated and tabulated. From the weight loss, the corrosion rate (mpy), inhibition efficiency (\%) and surface coverage $(\theta)$ of plant extract were calculated using the formula,

$$
\mathrm{CR}=\frac{534 W}{D A T}(\mathrm{mpy})
$$

where $W$-Weight loss in milligrams (mg), D-Density in grams per cubic centimeter $\left(\mathrm{g} / \mathrm{cm}^{3}\right), A$-Area of the specimen exposed in square inches $\left(\mathrm{in}^{2}\right)$ and $T$-Time of immersion in hours (h)

$$
\begin{gathered}
(\mathrm{IE} \%)=\left[1-\frac{\mathrm{CR} i}{\mathrm{CR} l}\right] \times 100, \\
\text { surface coverage }(\theta)=\left[1-\frac{\mathrm{CR} i}{\mathrm{CR} l}\right],
\end{gathered}
$$

where $\mathrm{CR} i$ and $\mathrm{CR} l$ are corrosion rates in the absence and presence of the inhibitors.

2.4. Characterization of the Coupons. A Philips model XL30SFEG scanning electron microscope with an energy dispersive X-ray analyzer attached was used in this study. It is a highly-resolution field emission scanning electron microscope with analytical capability. The surface analyses of the coupons before and after corrosion were analyzed for the morphology and the inhomogeneity in the chemical composition. The scanning electron microscope (SEM) was equipped with Energy Dispersive X-ray Spectrometry (EDS) [14].

2.5. Development of Mathematical Model. The experimentations were conducted as per standard L8 orthogonal array, so as to investigate which corrosion control parameters significantly affects the corrosion rate and the independently controllable predominant process parameters considered for the investigation are temperature, concentration and time. Two levels of each of the three factors were used for the statistical analysis. The levels for the three factors are entered in Table 1 and the treatment combinations for the two levels and three factors are tabulated in Table 2.

The model equation was obtained by representing the corrosion rate value by $\mathrm{CR}$, the response function can be expressed by equation below:

$$
\mathrm{CR}=f(A, B, C),
$$

where $A$ is the temperature, $B$ is the inhibitor and $C$ is the time. The model selected includes the effects of main variables first order and second-order interactions of all variables. Hence the general model is written as $[11,15]$

$$
\mathrm{CR}=\beta_{0}+\beta_{1} A+\beta_{2} B+\beta_{3} C+\beta_{4} A B+\beta_{5} A C+\beta_{6} B C+\beta_{7} A B C,
$$

where $\beta_{0}$ is average response of $\mathrm{CR}$ and $\beta_{1}, \beta_{2}, \beta_{3}, \beta_{4}, \beta_{5}$, $\beta_{6}$, and $\beta_{7}$ are coefficients associated with each variable $A, B$, and $C$ and interactions. The test results were recorded against the standard order of sequence as shown in Table 3. The sum of squares for main and interaction effects was calculated using Yates algorithm. The significant factors (main and interaction) were identified by analysis of variance (ANOVA) technique [16].

\section{Results and Discussion}

3.1. Results. In order to compare the factors that influence corrosion rate of mild steel in $0.5 \mathrm{M}$ sulphuric acid, the corrosion rate of the experimental specimens immersed in 
Table 1: Percentage of crude chemical constituents in the plants investigated.

\begin{tabular}{lcccccrr}
\hline S/No. & Plants & Alkaloids & Tannins & Saponins & Flavonoids & Steroids & Volatile \\
\hline 1 & A.S & $1.43 \pm 0.32$ & $15.25 \pm 0.11$ & $3.67 \pm 0.33$ & 0.00 & $0.65 \pm 0.12$ & $0.65 \pm 0.24$ \\
2 & A.T & $1.12 \pm 0.39$ & $13.45 \pm 0.34$ & $3.33 \pm 0.21$ & $0.98 \pm 0.33$ & $0.45 \pm 0.11$ & $0.86 \pm 0.56$ \\
3 & G.V & $1.21 \pm 0.45$ & $14.65 \pm 0.52$ & $2.99 \pm 0.87$ & $0.96 \pm 0.59$ & $0.43 \pm 10$ & $0.77 \pm 0.21$ \\
\hline
\end{tabular}

TABLE 2: Result of corrosion rate without and with inhibitor at different temperature and time.

\begin{tabular}{|c|c|c|c|c|}
\hline \multirow{2}{*}{$\begin{array}{l}\text { Inhibitor concentration } \\
(\% \mathrm{v} / \mathrm{v})\end{array}$} & \multicolumn{4}{|c|}{ Mild steel corrosion rate (mpy) } \\
\hline & $30^{\circ} \mathrm{C}$ & $50^{\circ} \mathrm{C}$ & $70^{\circ} \mathrm{C}$ & Time (mins) \\
\hline 0 & 51.71 & 62.41 & 70.43 & \multirow{6}{*}{135} \\
\hline 2 & 23.26 & 28.72 & 35.20 & \\
\hline 4 & 17.06 & 21.84 & 27.16 & \\
\hline 6 & 14.47 & 19.35 & 25.35 & \\
\hline 8 & 11.94 & 17.47 & 21.14 & \\
\hline 10 & 11.02 & 14.09 & 18.61 & \\
\hline 0 & 49.81 & 60.23 & 69.11 & \multirow{6}{*}{180} \\
\hline 2 & 16.28 & 23.08 & 28.81 & \\
\hline 4 & 9.93 & 12.69 & 17.23 & \\
\hline 6 & 8.61 & 11.88 & 14.71 & \\
\hline 8 & 6.92 & 10.82 & 13.15 & \\
\hline 10 & 7.18 & 9.98 & 12.74 & \\
\hline 0 & 43.63 & 56.41 & 63.60 & \multirow{6}{*}{270} \\
\hline 2 & 10.57 & 14.54 & 17.95 & \\
\hline 4 & 8.29 & 10.72 & 13.35 & \\
\hline 6 & 6.83 & 10.35 & 12.50 & \\
\hline 8 & 6.61 & 8.95 & 10.27 & \\
\hline 10 & 6.73 & 8.79 & 10.23 & \\
\hline
\end{tabular}

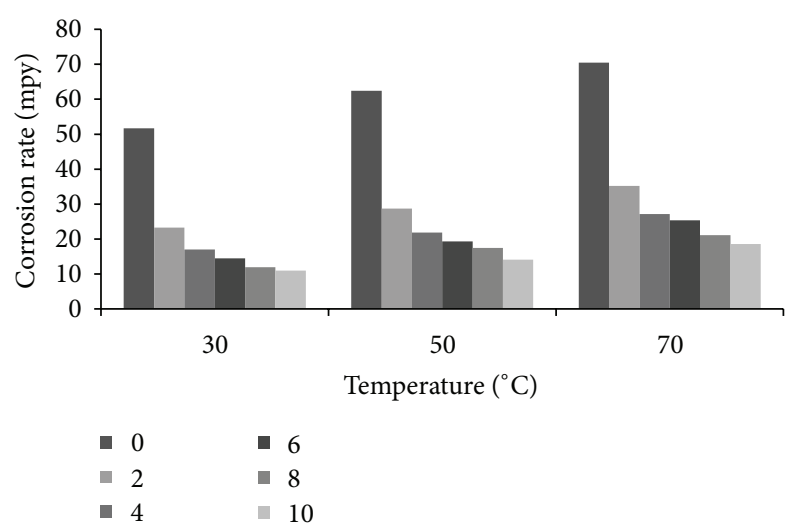

FIGURE 1: Variation of corrosion rate with temperature after 135 minutes of exposure time.

the corrosive reagent with and without inhibitor at varied temperature and time were determined using (1) above were shown in Figures 1, 2, 3, 4, 5, 6, and 7.

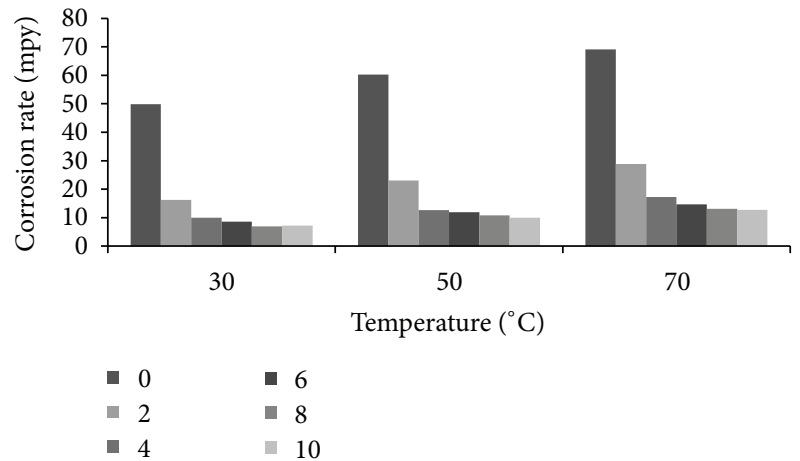

FIGURE 2: Variation of corrosion rate with temperature after 180 minutes of exposure time.

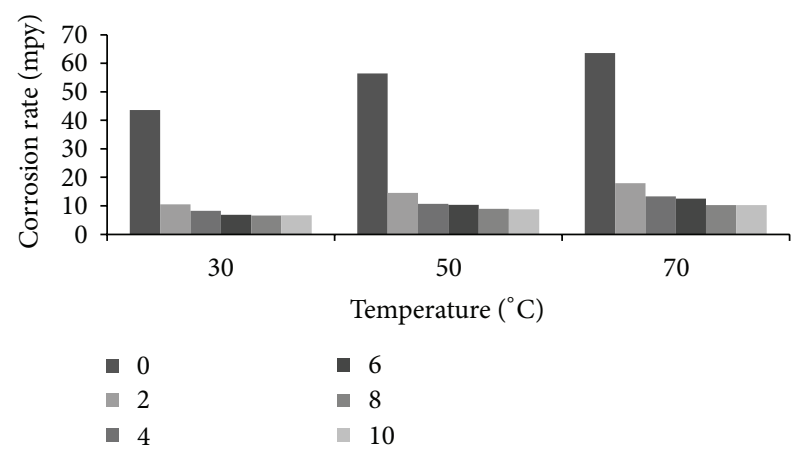

FIGURE 3: Variation of corrosion rate with temperature after 270 minutes of exposure time.

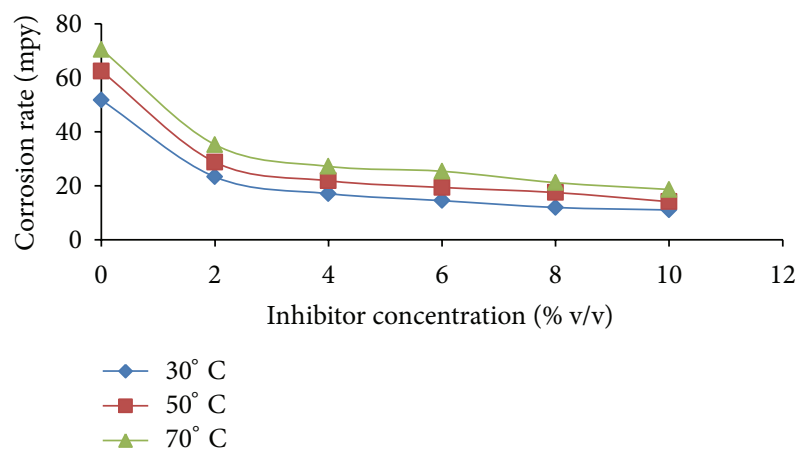

FIGURE 4: Variation of corrosion rate with inhibitor concentration after 135 minutes exposure time. 
TABLE 3: Result of apparent activation energy for the absence and presence of inhibitor at different exposure time.

\begin{tabular}{lcc}
\hline $\begin{array}{l}\text { Inhibitor } \\
\text { concentration } \\
(\% \mathrm{v} / \mathrm{v})\end{array}$ & Mild steel (apparent activation energy, KJ/mol) \\
\hline 0 & 2.55 & Time (mins) \\
2 & 4.77 & \\
4 & 5.73 & 135 \\
6 & 10.19 & \\
8 & 10.21 & \\
10 & 10.95 & \\
\hline 0 & 2.45 & \\
2 & 4.62 & \\
4 & 5.65 & \\
6 & 10.02 & \\
8 & 10.15 & \\
10 & 10.75 & \\
0 & 2.35 & \\
2 & 4.45 & \\
4 & 5.55 & \\
6 & 9.96 & \\
8 & 10.02 & \\
10 & 10.44 & \\
\hline
\end{tabular}

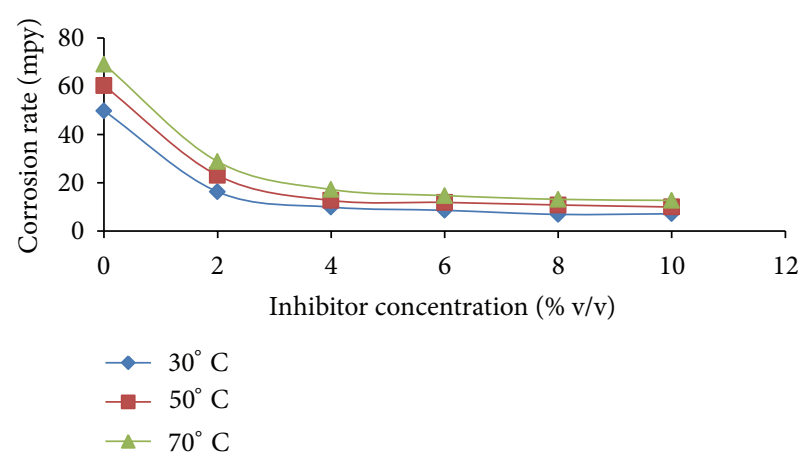

FIGURE 5: Variation of corrosion rate with inhibitor concentration after 180 minutes exposure time.

3.1.1. Kinetics Studies. Although, kinetics models are useful tool to discuss the mechanism of corrosion inhibition of grewa venusta. Arrhenius equation was used to determine the corrosion rate using the expression in (4) and also presented in Figures 8-9

$$
A=A_{o} e^{-E a / R T} .
$$

The logarithm of $A$ could be represented as a linear equation given below in (5)

$$
\ln A=-\frac{E a}{R T}+\ln A_{o} .
$$

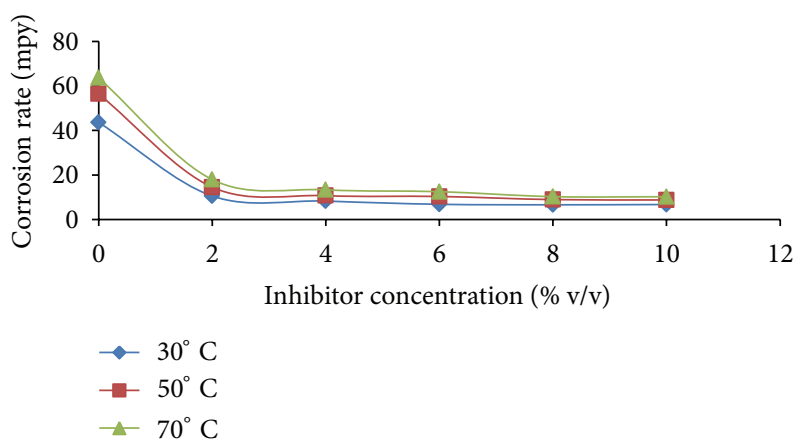

FIGURE 6: Variation of corrosion rate with inhibitor concentration after 270 minutes exposure time.

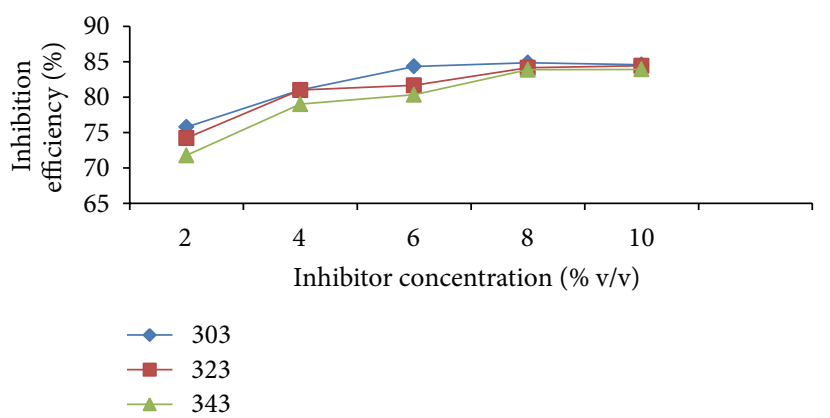

FIGURE 7: Variations of IE \% against concentration of G.V after 270 minutes of exposure at 30,50 , and $70^{\circ} \mathrm{C}$.

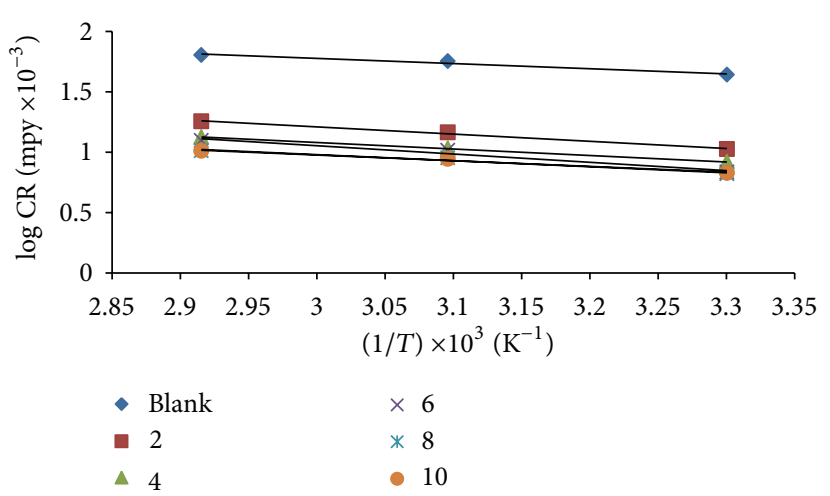

FIGURE 8: $\log \mathrm{CR}$ against 1/Temperature for mild steel dissolution process in $0.5 \mathrm{M} \mathrm{H}_{2} \mathrm{SO}_{4}$ containing different concentrations of Grewa venusta at 30,50 , and $70^{\circ} \mathrm{C}$.

3.1.2. SEM/EDS. The morphology of the polished, with and without inhibitor of grewa venusta were examined and presented in Figures 10-12.

3.1.3. Development of Model. The results of the statistical model were shown in Tables 7-9 and Figure 13 showed the graph of actual values and predicted values.

3.2. Discussion. Figures 1-3 showed the variation of corrosion rate with temperature after 135, 180 and 270 minutes and 


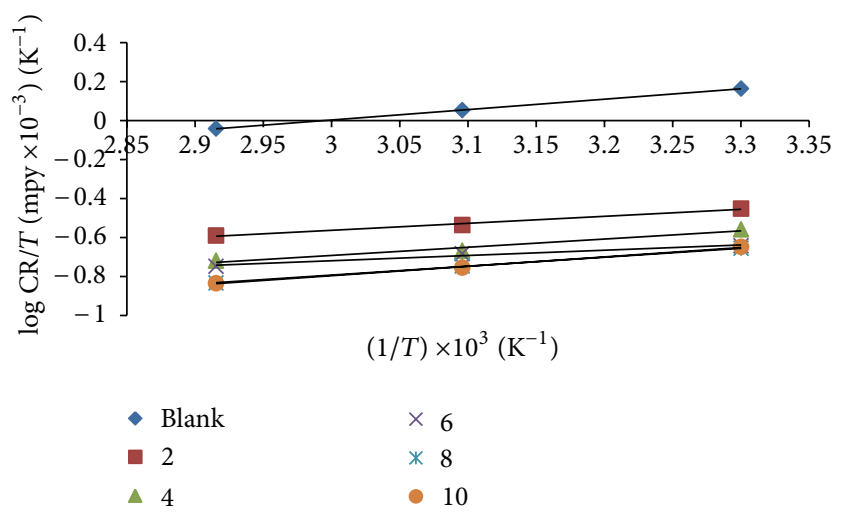

FIGURE 9: $\log \mathrm{CR} / \mathrm{T}$ against 1/Temperature for mild steel dissolution process in $0.5 \mathrm{M} \mathrm{H}_{2} \mathrm{SO}_{4}$ containin different concentrations of grewa venusta at 30,50 , and $70^{\circ} \mathrm{C}$.

TABLE 4: Factorial design of the corrosion rate.

\begin{tabular}{lcc}
\hline Factors & Low level & High level \\
\hline Temperature $(A)$ & $30^{\circ} \mathrm{C}$ & $70^{\circ} \mathrm{C}$ \\
Inhibitor $(B)$ & 0 & $10 \% \mathrm{v} / \mathrm{v}$ \\
Time $(C)$ & 45 minutes & 270 minutes \\
\hline
\end{tabular}

also in Table 4, it can be seen from these figures and table that the corrosion rate increases with increasing temperature while increase in the plant extract leads to decrease in corrosion rate. From the figures; corrosion rate of 70.43, 69.11 and $63.60 \mathrm{mpy}$ on the specimen immersed in the absence of inhibitor when the temperature was raised from 30 to $70^{\circ} \mathrm{C}$ at exposure time of 135, 180 and 270 minutes respectively while corrosion rate of $11.02,7.18$ and $6.61 \mathrm{mpy}$ at an experimental temperature of $30^{\circ} \mathrm{C}$ when the inhibitor concentration were raised from 2 to $10 \% \mathrm{v} / \mathrm{v}$ at an exposure time of 135, 180 and 270 minutes. The figures indicated that temperature, inhibitor and time are significant parameters for the corrosion rate control. Variation of corrosion rate with inhibitor concentration after 135, 180 and 270 minutes of exposure time were shown in Figures 4-6 also confirm that corrosion rates decrease with increase in inhibitor concentration and increase with increase in temperature. This also supported the findings of $[8,9,17]$. Figure 7 shows the variation of inhibition efficiency (IE \%) against Concentration of grewa venusta after 270 mins of exposure at 30,50 and $70^{\circ} \mathrm{C}$. From the Table 5, it can be concluded that the presence of phytochemical constituents (tannins, alkaloids, saponins, flavonoids) were responsible for the reduction of corrosion rate thereby increasing the efficiency (IE \%) of the extract. This is also in support of the findings of $[5,12,18]$.

Figures 8-9 show the linear regression of $\log C R$ and $1 / T$ and $\log C R / T$ and $1 / T$ for the specimen immersed in sulphuric acid with and without inhibitor [5, 6]. From the Table 6, the results showed that the apparent activation energy in the absence of inhibitor is lower than that in the presence of the inhibitor which implies physiorption adsorption isotherm $[7,8]$ and this suggests that the anticorrosion inhibitor is very active for mild steel in acidic medium.
TABLE 5: Factorial design of the corrosion process showing treatment combination.

\begin{tabular}{lccc}
\hline $\begin{array}{l}\text { Experimental } \\
\text { no. }\end{array}$ & $\begin{array}{c}\text { Temperature } \\
\text { level }\end{array}$ & $\begin{array}{c}\text { Concentration } \\
\text { level }\end{array}$ & Time level \\
\hline 1 & -1 & -1 & -1 \\
$A$ & +1 & -1 & -1 \\
$B$ & -1 & +1 & -1 \\
$A B$ & +1 & +1 & -1 \\
$C$ & -1 & -1 & +1 \\
$A C$ & +1 & -1 & +1 \\
$B C$ & -1 & +1 & +1 \\
$A B C$ & +1 & +1 & +1 \\
\hline
\end{tabular}

Coded $=-1$ (low level), +1 (upper level or high).

Figures 10-12 show different morphologies structures of the coupons of polished, without and with inhibitor. The morphology of the uninhibited surface was altered during corrosion and as expected rough, uneven surface covered and pits and cracks were seen (see Figure 11). However, no pits and cracks were observed in the morphologg of sample with inhibitor (see Figure 12). The protective film formed on the surface of the mild steel was confirmed by SEM studies. Where as in the presence of the optimum extract, mild steel immersed in acidic medium plant extract show the presence of a protective film and smooth surfaces over the surface of the mild steel in the presence of the inhibitor as shown in Figure 12. This shows that the plant extracts inhibit corrosion of mild steel in acidic solution. This is in line with earlier work of $(3,19)$.

The results of ANOVA were presented in Table 7, the analysis was evaluated for a confidence level of 95\%, that is for significance level of $\alpha=0.05$. It can be observed from the results obtained that inhibitor was the most significant parameter having the highest statistical influence $(73.28 \%)$ on the corrosion control followed by time $16.39 \%$ and temperature $7.48 \%$ respectively.

When the $F$-value for the models was less than 0.05 , then the parameter or interaction can be considered as statistically significant [19]. From Table 8, it is observed that the temperature $(A)$, inhibitor $(B)$ and time $(C)$ are significant model terms influencing corrosion rate of mild steel. Although the interaction effect of temperature with inhibitor $(A B)$ and inhibitor with time $(B C)$ were considered statistically insignificant since their $F$-values are greater than 0.05 , and hence they are neglected. The coefficient of determination $\left(R^{2}\right)$ is defined as the ratio of the explained variation to the total variation. It is a measure of the degree of fitness. When coefficient of determination $R^{2}$ approaches unity, a better response model results and it fits the actual data. The value of $R^{2}$ calculated for this model was 0.9165 which means that the developed model has high correlation with the experimental value. It demonstrates that $91.65 \%$ of the variability in the data can be explained by this model. Thus, it confirmed that the model provides reasonably good explanation of the relationship between the independent factors and their responses [20]. A multiple linear regression model developed 
TABLE 6: Experimental condition and corrosion rate for each shown condition using A.S. extract

\begin{tabular}{lcccc}
\hline Experimental condition & Temperature level $\left({ }^{\circ} \mathrm{C}\right)$ & Concentration level $(\% \mathrm{v} / \mathrm{v})$ & Time level $(\mathrm{mins})$ & Corrosion rate $\left(\mathrm{mpy} \times 10^{-2}\right)$ \\
\hline 1 & 30 & 0 & 45 & 43.63 \\
$A$ & 70 & 0 & 45 & 75.32 \\
$B$ & 30 & 10 & 45 & 38.52 \\
$A B$ & 70 & 10 & 270 & 63.60 \\
$C$ & 30 & 0 & 270 & 26.48 \\
$A C$ & 70 & 0 & 270 & 59.65 \\
$B C$ & 30 & 10 & 270 & 6.73 \\
$A B C$ & 70 & 10 & 10.23 \\
\hline
\end{tabular}

TABLE 7: Analysis of variance (ANOVA) for corrosion rate in the presence of Grewia venusta extract.

\begin{tabular}{|c|c|c|c|c|c|c|}
\hline Source of variation & Sum of squares & Degree of freedom (DF) & Mean square & $F_{\mathrm{cal}}=\mathrm{Ms} /$ Error Ms & $F$-value & $F(\%)$ \\
\hline \multicolumn{7}{|l|}{ Main effect } \\
\hline$A$ & 327.42 & 1 & 327.42 & 28.65 & 0.0332 & 7.48 \\
\hline$B$ & 3209.61 & 1 & 3209.61 & 280.86 & 0.0035 & 73.28 \\
\hline C & 717.83 & 1 & 717.83 & 62.81 & 0.0155 & 16.39 \\
\hline \multicolumn{7}{|l|}{ Interaction } \\
\hline$A B$ & 50.50 & 1 & 50.50 & 4.42 & 0.1703 & 1.15 \\
\hline$B C$ & 51.51 & 1 & 51.51 & 4.51 & 0.1677 & 1.18 \\
\hline Residual & 22.86 & 2 & 11.43 & & & 0.52 \\
\hline Cor. Total & 4379.73 & 7 & & & & 100 \\
\hline
\end{tabular}

TABLE 8: Effect of the variables at 95\% confidence level for Grewia venusta extract.

\begin{tabular}{|c|c|c|c|c|c|}
\hline Factor & Coefficient estimate & Degree of freedom & Standard error & 95\% CI low & 95\% CI high \\
\hline Intercept & 40.52 & 1 & 1.20 & 35.58 & 45.66 \\
\hline $\begin{array}{l}\text { Temperature }(\mathrm{A}) \\
1.00\end{array}$ & 6.40 & 1 & 1.20 & 1.26 & 11.54 \\
\hline $\begin{array}{l}\text { Inhibitor }(B) \\
1.00\end{array}$ & -20.03 & 1 & 1.20 & -25.17 & -14.89 \\
\hline $\begin{array}{l}\text { Time }(C) \\
1.00\end{array}$ & -9.47 & 1 & 1.20 & -14.61 & -4.33 \\
\hline $\begin{array}{l}\mathrm{AB} \\
1.00\end{array}$ & -2.51 & 1 & 1.20 & -7.65 & 2.63 \\
\hline $\begin{array}{l}\mathrm{BC} \\
1.00 \\
\end{array}$ & -2.54 & 1 & 1.20 & -7.68 & 2.60 \\
\hline
\end{tabular}

TABLE 9: Comparison of the actual and the predicted result for mild steel using Grewia venusta.

\begin{tabular}{|c|c|c|c|c|c|c|}
\hline \multirow{2}{*}{ Exp. no. } & \multirow{2}{*}{ Temperature $\left({ }^{\circ} \mathrm{C}\right)$} & \multirow{2}{*}{ Inhibitor (\% v/v) } & \multirow{2}{*}{ Time (mins) } & \multicolumn{3}{|c|}{ Corrosion rate $\left(\mathrm{mpy} \times 10^{-3}\right)$} \\
\hline & & & & Actual & Predicted & Residual \\
\hline S11 & -1 & -1 & -1 & 59.65 & 58.58 & 1.07 \\
\hline $\mathrm{S} 12$ & +1 & -1 & -1 & 75.32 & 76.40 & -1.08 \\
\hline S13 & -1 & +1 & -1 & 26.48 & 28.62 & -2.14 \\
\hline S14 & +1 & +1 & -1 & 38.52 & 36.38 & 2.14 \\
\hline S15 & -1 & -1 & +1 & 43.63 & 44.71 & -1.08 \\
\hline S16 & +1 & -1 & +1 & 63.60 & 62.53 & 1.07 \\
\hline S17 & -1 & +1 & +1 & 6.73 & 4.60 & 2.13 \\
\hline S18 & +1 & +1 & +1 & 10.23 & 12.37 & -2.14 \\
\hline
\end{tabular}


c: \edax32\genesis\genmaps.spc 08-Dec-2011 17:35:19
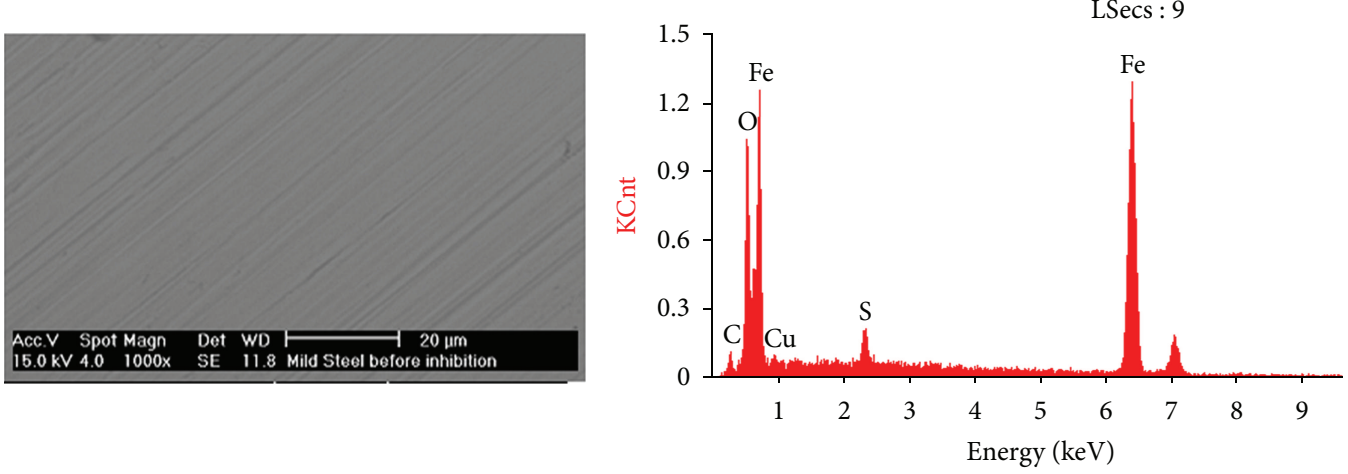

FIGURE 10: SEM/EDS microstructure of mild steel before corrosion test.

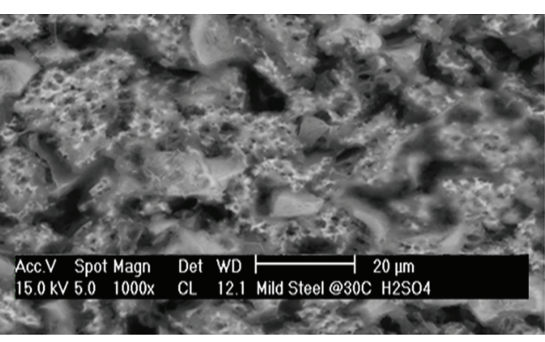

c:ledax32\genesis\genmaps.spc 08-Dec-2011 17:55:05

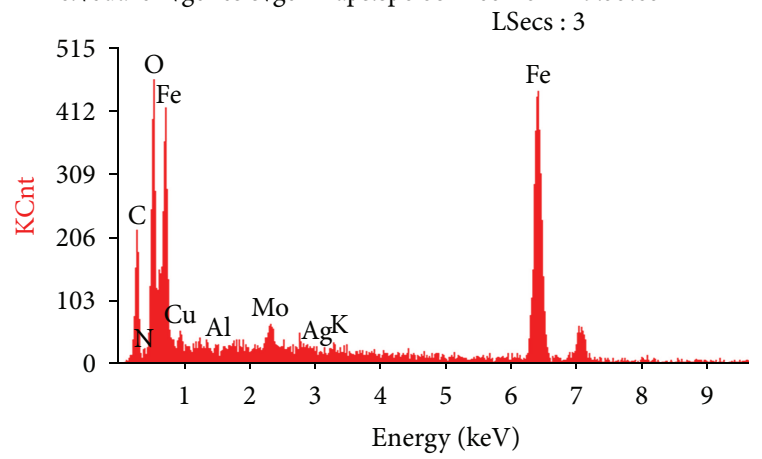

FIGURE 11: SEM/EDX microstructure of mild steel immersed in $0.5 \mathrm{M} \mathrm{H}_{2} \mathrm{SO}_{4}$.

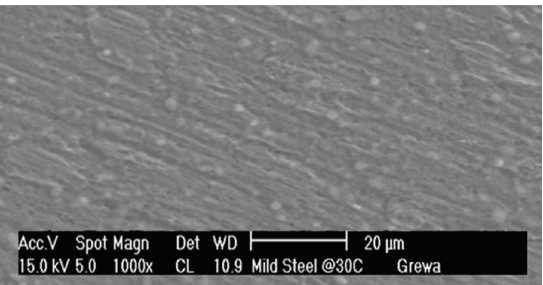

c: \edax32\genesis \genmaps.spc 08-Dec-2011 18:14:56

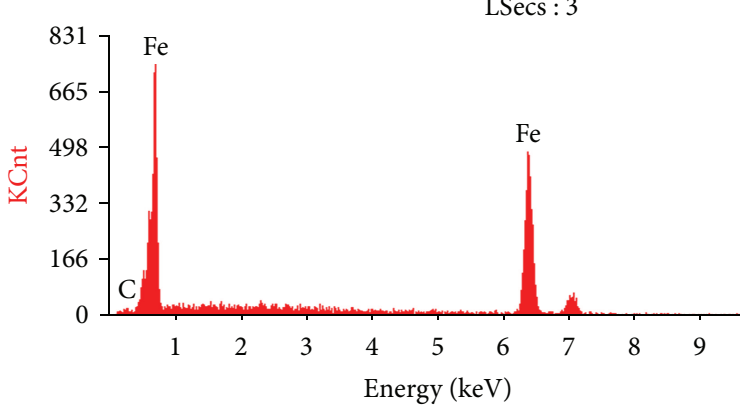

FIGURE 12: SEM/EDX micrograph of mild steel immersed in $0.5 \mathrm{M} \mathrm{H}_{2} \mathrm{SO}_{4}+10 \% \mathrm{v} / \mathrm{v}$ G.V. 


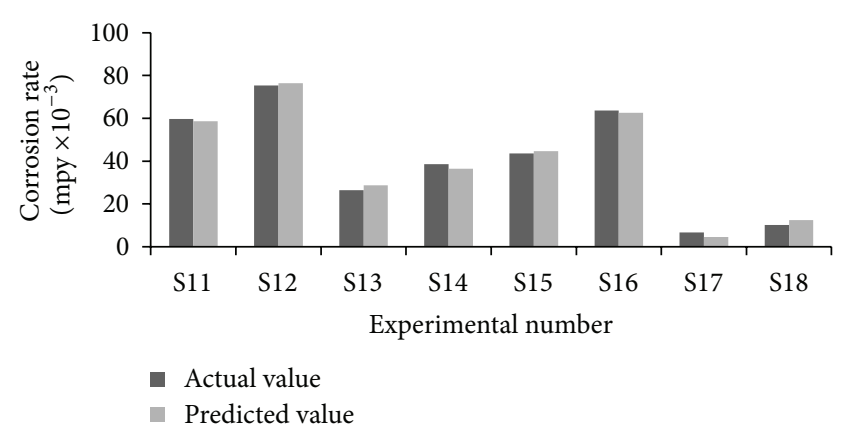

FIGURE 13: Variation of experimental number with corrosion rate for mild steel with G.V.

and the effect of $95 \%$ confidence levels for the extract was presented in Table 8. A regression equation thus generated establishes correlation between the significant terms obtained from ANOVA, namely, temperature, inhibitor and time. Therefore, it was concluded that the influence of temperature, inhibitor concentration and time on the corrosion rate were statistically significant. The model equation was obtained after calculating each of the coefficients of (7). The developed models equations for the corrosion behaviour of the mild steel in the acidic environment in the presence of the extract can be expressed as:

$$
\mathrm{CR}(\mathrm{G} . \mathrm{V})=40.52+6.40 A-20.03 B-9.47 C-2.51 A B-2.54 B C \text {. }
$$

The results of linear regression model was presented in Table 8 for the extract of G.V which showed that the inhibitor appears to be the most important variable with main effect of $-20.03 \mathrm{mpy}$ followed by time $(C)$ with $-9.47 \mathrm{mpy}$ and temperature $(A)$ with 6.40 mpy. Similar results have been observed by [11, 21, 22].

The results of linear regression model Table 8 for the extract of G.V showed that the inhibitor appears to be the most important variable with main effect of -20.03 mpy followed by time $(C)$ with -9.47 mpy and temperature $(A)$ with $6.40 \mathrm{mpy}$. The regression revealed that raising the temperature from 30 to $70^{\circ} \mathrm{C}$ would result in an increase in the corrosion rates by $6.40 \mathrm{mpy}$ while raising the time from 45 to 270 minutes would result to decrease in corrosion rates by $9.47 \mathrm{mpy}$ and increasing the inhibitor concentrations from 0 to $10 \% \mathrm{v} / \mathrm{v}$ would also result to decrease in the corrosion rates by 20.03 mpy respectively.

The interaction effect of the variables temperature, inhibitor concentration and time are also quite significant and one must take into account these factors for predicting the combined effect of temperature, inhibitor and time on the corrosion rate of the material. The interactive effects are between temperature and inhibitor concentration $(A B)$ and inhibitor concentration and time $(B C)$ are -2.51 and $-2.54 \mathrm{mpy}$. Similar results have been observed by $(17,22,23)$.

In order to validate the regression model, confirmation test was conducted with parameter levels that were used for analysis. The different parameter levels chosen for the confirmation test are shown in Table 9. Residual variation estimated in (8) for the corrosion rate is in the range of -2.24 to 2.13. The results of the confirmation tests were obtained and comparisons were made between the actual corrosion rate values and the predicted values obtained from the regression models as shown in Table 9. The residual (error) associated with the relationship between the experimental values and the computed values from the regression models for mild steel were very less (less than $4 \%$ error). This is in line with findings of [23]. Hence, the regression models developed demonstrated feasible and effective way to predict the corrosion rate of the mild steel. Thus the developed equations can be used to predict corrosion for any combination of factor levels in the specified range. The actual and predicted corrosion rates values are presented in the form of histogram in Figure 13.

\section{Conclusion}

(1) Experimental data showed that in the presence of different concentration $(2-10 \% \mathrm{v} / \mathrm{v})$, plant extract grewa venusta inhibited the corrosion of mild steel in acidic medium. The inhibition efficiency increased with increase in the extracts concentration and with decrease in temperature leading to a physical adsorption.

(2) The highest efficiency of $86.47 \%$ was observed at the optimum of $8 \% \mathrm{v} / \mathrm{v}$ for grewa venusta extract in the acid solution and the effect of immersion time of the plant extracts at these optimums was attained at 180 minutes immersion time at $30^{\circ} \mathrm{C}$ which was sufficient for pickling process.

(3) The value of activation energy Ea calculated from Arrhenius equations revealed that $\mathrm{Ea}$ increases in presence of the plant extract in the acid solution and $<80 \mathrm{KJ} / \mathrm{molK}$, suggesting that the corrosion inhibition occurred through physical adsorption.

(4) The SEM micrographs revealed the presence of a protective layers over the metal surface in the presence of the extracts through an adsorption process, hence confirmed the high performance of inhibitive effect of the plant extract.

(5) EDS results also showed an enhancement of iron in the presence of the extract of grewa venusta.

(6) ANOVA results revealed that the parameters $(A$, $B$, and $C$ ) are statistically significant with $F$-values less than 0.05 and $F(\%)$ for the inhibitor grewa venusta are greater than 70 followed by time which is greater than 16 and temperature greater than 7 . The interactions exhibited only minor influence and not statistically significant.

(7) The results obtained by regression equations closely correlate each other which validate the regression equations developed. A good agreement between the predicted and actual corrosion rate was observed.

(8) The results obtained from the statistical analysis are in good agreement with the experimental findings for 
the temperature, inhibitor and time. It was found that corrosion rate increases with increasing temperature and decrease with increase in both the inhibitor and time.

(9) The developed mathematical models can be used to predict the corrosion values in terms of corrosion control process parameters obtained from any combinations within the ranges studied and also employed for optimization of the process parameters of mild steel with respect to corrosion control values.

(10) The gravimetric method is in a good agreement with the statistical analysis and this improves the validity of the overall results obtained.

\section{References}

[1] R. Tripathi, A. Chaturvedi, and R. K. Upadhayay, "Corrosion inhibitory effects of some substituted thiourea on mild steel in acid media," Research Journal of Chemical Sciences, vol. 2, no. 2 , pp. 18-27, 2012.

[2] S. Rekkab, H. Zarrok, R. Salghi et al., "Green corrosion inhibitor from essential oil of Eucalyptus globulus (Myrtaceae) for C38 steel in sulfuric acid solution," Journal of Materials and Environmental Science, vol. 3, no. 4, pp. 613-627, 2012.

[3] A. Ostovari, S. M. Hoseinieh, M. Peikari, S. R. Shadizadeh, and S. J. Hashemi, "Corrosion inhibition of mild steel in 1 $\mathrm{M} \mathrm{HCl}$ solution by henna extract: a comparative study of the inhibition by henna and its constituents (Lawsone, Gallic acid, $\alpha$-d-Glucose and Tannic acid)," Corrosion Science, vol. 51, no. 9, pp. 1935-1949, 2009.

[4] S. A. Abd El-Maksoud, "The effect of organic compounds on the electrochemical behaviour of steel in acidic media. A review," International Journal of Electrochemical Science, vol. 3, no. 5, pp. 528-555, 2008.

[5] A. Begum, S. Harikrishna, I. Khan, and K. Veena, "Enhancement of the inhibitor efficiency of atropine methochloride in corrosion control of mild steel in sulphuric acid," E-Journal of Chemistry, vol. 5, no. 4, pp. 774-781, 2008.

[6] A. A. Rahim and J. Kassim, "Recent development of vegetal tannins in corrosion protection of iron and steel," Recent Patents on Materials Science, vol. 1, no. 3, pp. 223-231, 2008.

[7] A. M. Al-Turkustani, S. T. Arab, and R. H. Al-Dahiri, "Aloe plant extract as environmentally friendly inhibitor on the corrosion of aluminum in hydrochloric acid in absence and presence of iodide ions," Modern Applied Science, vol. 4, no. 5, pp. 105-124, 2010.

[8] A. Singh, V. K. Singh, and M. A. Quraishi, "Aqueous extract of kalmegh (Andrographis paniculata) leaves as green inhibitor for mild steel in hydrochloric acid solution," International Journal of Corrosion, vol. 2010, Article ID 275983, 10 pages, 2010.

[9] C. A. Loto, R. T. Loto, and A. Popoola, "Synergistic effect of tobacco and kola tree extracts on the corrosion inhibition of mild steel in acid chloride," International Journal of Electrochemcal Science, vol. 6, no. 9, pp. 3830-3843, 2011.

[10] B. O. Obadoni and P. O. Ochuko, "Phytochemical studies and comparative efficacy of the crude extracts of some haemostatic plants in edo and delta states of Nigeria," Global Journal of Pure and Applied Sciences, vol. 8, no. 2, pp. 203-208, 2001.

[11] O. B. Oloche, S. A. Yaro, and E. G. Okafor, "Analytical correlation between varying corrosion parameters and corrosion rate of $\mathrm{Al}-4.5 \mathrm{Cu} / 10 \% \mathrm{ZrSiO}_{4}$ composite in hydrochloric acid by rare earth chloride," Journal of Alloys and Compounds, vol. 472, no. 1-2, pp. 178-185, 2009.

[12] A. M. Abdel-Gaber, B. A. Abd-El-Nabey, and M. Saadawy, "The role of acid anion on the inhibition of the acidic corrosion of steel by lupine extract," Corrosion Science, vol. 51, no. 5, pp. 10381042, 2009.

[13] G. Ilayaraja, A. R. Sasieekhumar, and P. Dhanakodi, "Inhibition of mild steel corrosion in acidic medium by aqueous extract of tridax procumbens L," E-Journal of Chemistry, vol. 8, no. 2, pp. 685-688, 2011.

[14] J. B. Wachtman and R. A. Haber, Ceramic Films and Coatings, Noyes Publications, Park Ridge, NJ, USA, 1993.

[15] V. S. Aigbodion, S. B. Hassan, E. T. Dauda, and R. A. Mohammed, "The development of mathematical model for the prediction of ageing behaviour for $\mathrm{Al}-\mathrm{Cu}-\mathrm{Mg} / \mathrm{bagasse}$ ash particulate composites," Journal of Minerals and Materials Characterization \& Engineering, vol. 9, no. 10, pp. 907-917, 2010.

[16] I. Miller and J. E. Freund, Probability and Statistics for Engineers, Prentice Hall India, New Delhi, India, 2001.

[17] L. E. Umoru, I. A. Fawehinmi, and A. Y. Fasasi, "Investigation of the inhibitive influence of theobroma cacao and cola acuminata leaves extracts on the corrosion of a mild steel in sea water," Journal of Applied Sciences Research, vol. 2, no. 4, pp. 200-204, 2006.

[18] N. O. Obi-Egbedi, K. E. Essien, and I. B. Obot, "Computational simulation and corrosion inhibitive potential of alloxazine for mild steel in 1M HCl," Journal of Computational Methods in Molecular Design, vol. 1, no. 1, pp. 26-43, 2011.

[19] S. M. Ross, Introduction to Probability and Statistics for Engineers and Scientists, Elsevier Academic Press, 3rd edition, 2004.

[20] S. Venkat Prasat, R. Subramanian, N. Radhika, B. Anandavel, L. Arun, and N. Praveen, "Influence of parameters on the dry sliding wear behaviour of aluminium/fly ash/graphite hybrid metal matrix composites," European Journal of Scientific Research, vol. 53, no. 2, pp. 280-290, 2011.

[21] E. E. Oguzie, "Corrosion inhibitive effect and adsorption behaviour of Hibiscus sabdariffa extract on mild steel in acidic media," Portugaliae Electrochimica Acta, vol. 26, no. 3, pp. 303314, 2008.

[22] M. A. Amin, S. S. Abd El-Rehim, E. E. F. El-Sherbini, and R. S. Bayoumi, "Chemical and electrochemical (AC and DC) studies on the corrosion inhibition of low carbon steel in $1.0 \mathrm{M} \mathrm{HCl}$ solution by succinic acid-temperature effect, activation energies and thermodynamics of adsorption," International Journal of Electrochemcal Science, vol. 3, no. 2, pp. 199-215, 2008.

[23] P. G. Kochure and K. N. Nandurkar, "Mathematical modeling for selection of process parameters in induction hardening of EN8 D steelJournal of Mechanical and Civil Engineering," vol. 1, no. 2, pp. 28-32, 2012. 

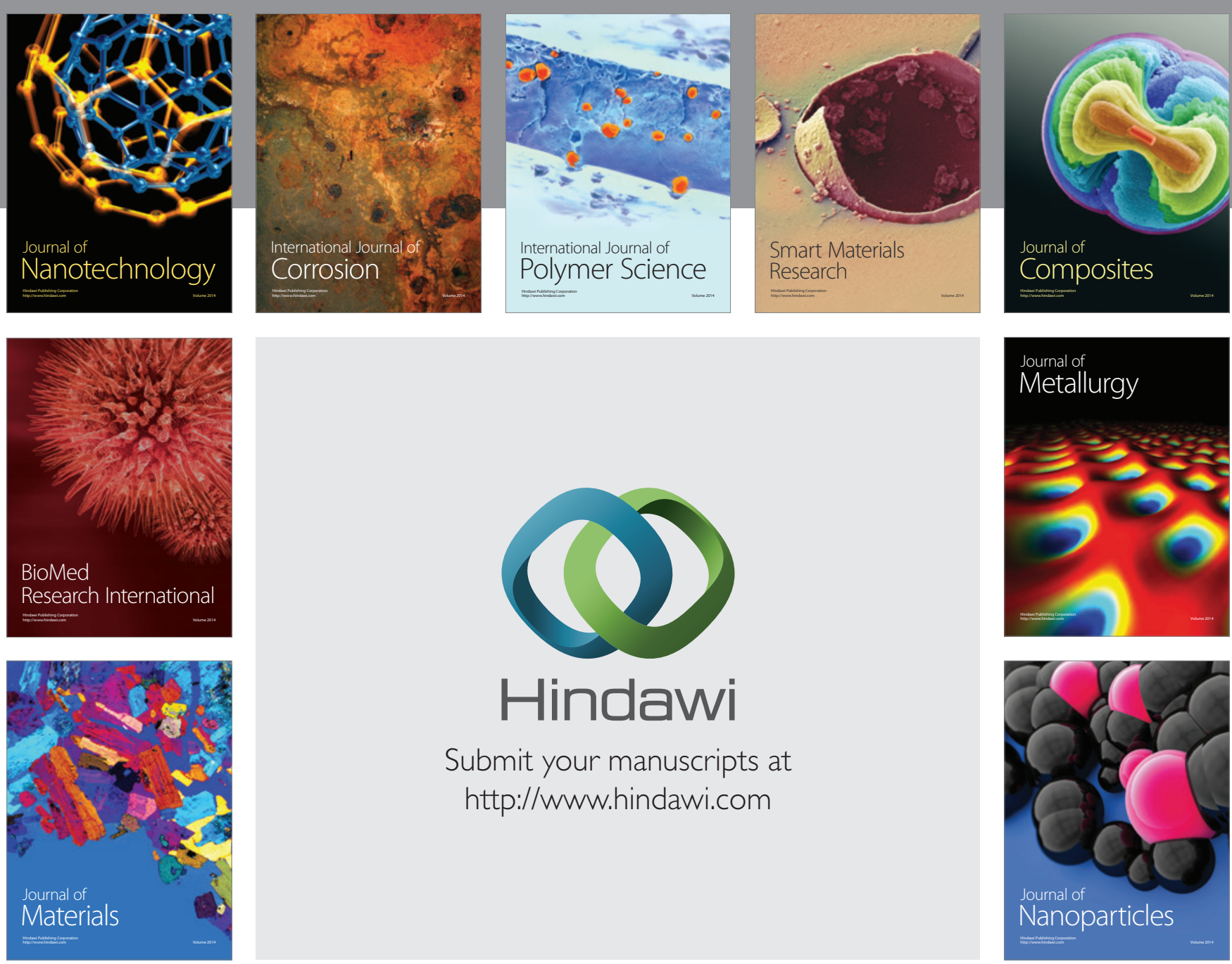

Submit your manuscripts at http://www.hindawi.com
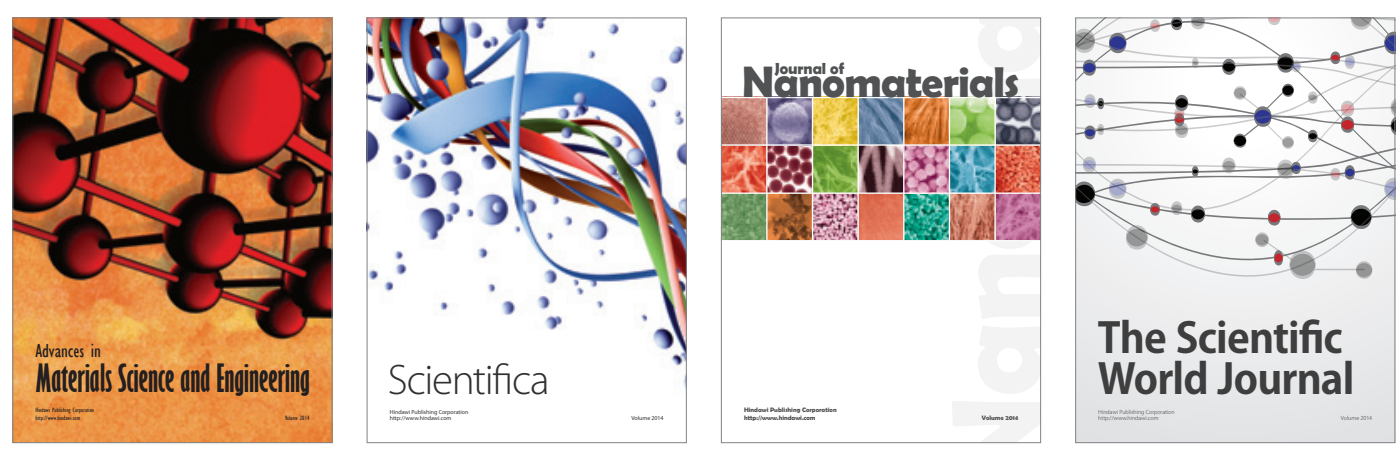

\section{The Scientific World Journal}
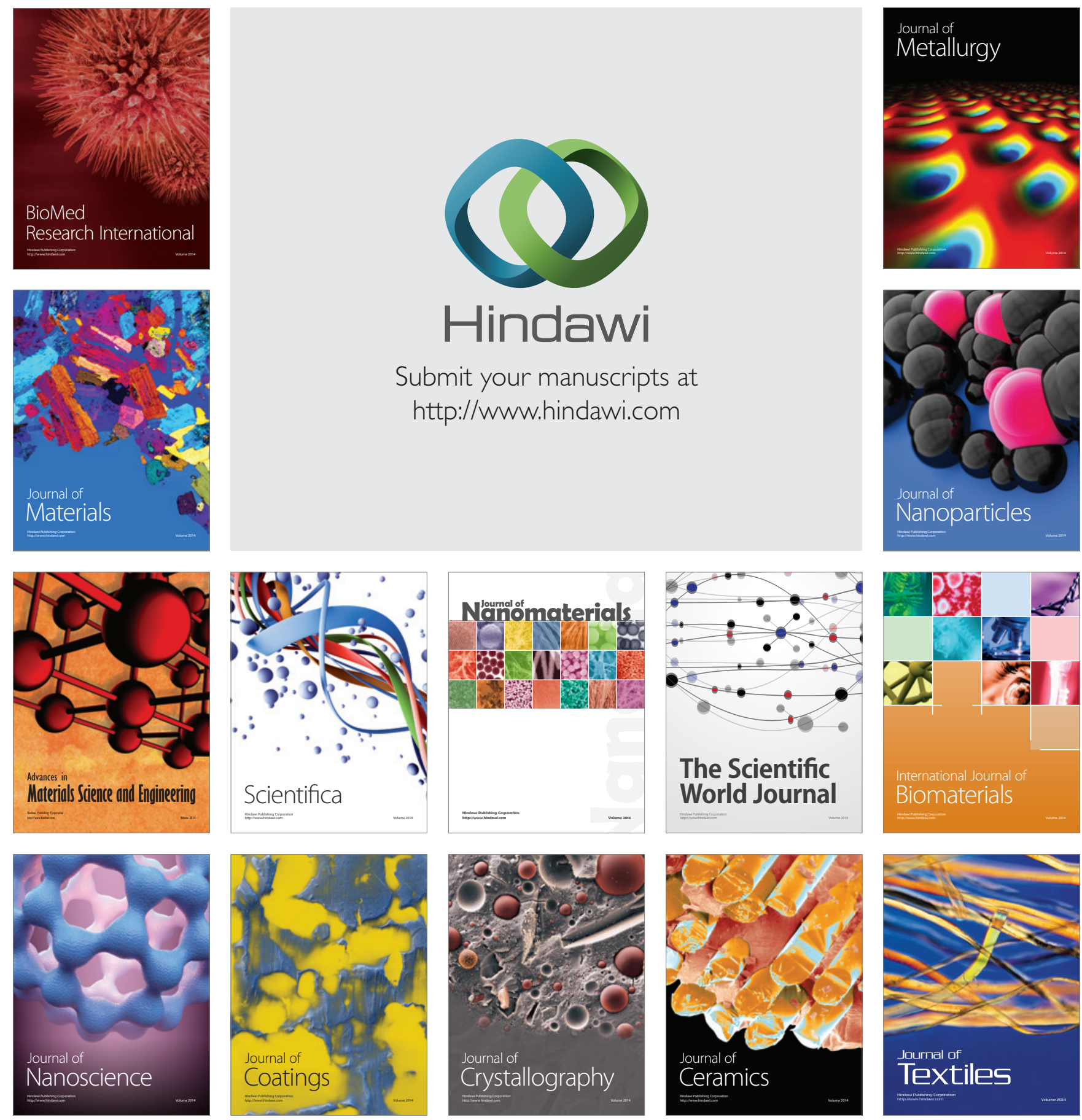